\title{
The Importance of Understanding Parental Perception When Treating Primary Nocturnal Enuresis: A Topic Review and an Institutional Experience
}

\author{
Thomson T Tai ${ }^{1}$ \\ Brent $\mathrm{T} \mathrm{Tai}^{2,3}$ \\ Yu-Jun Chang (D) $^{2}$ \\ Kuo-Hsuan Huang ${ }^{4,5}$ \\ 'Department of Surgery, Creighton \\ University, Phoenix, AZ, USA; \\ ${ }^{2}$ Department of Epidemiology and \\ Biostatistics, Changhua Christian \\ Hospital, Changhua, Taiwan; ${ }^{3}$ Burrell \\ College of Osteopathic Medicine, Las \\ Cruces, NM, USA; ${ }^{4}$ Department of \\ Surgery, Erlin Christian Hospital, \\ Changhua, Taiwan; ${ }^{5}$ Division of Urology, \\ Changhua Christian Hospital, Changhua, \\ Taiwan
}

\begin{abstract}
Primary nocturnal enuresis (PNE) is a common childhood disorder that adversely affects a child's mental well-being and social life. Our clinical experience showed parents and their child often have significantly different perspective of enuresis, and these differences can affect family dynamics, treatment approaches, and treatment success. Parents' perception of PNE also influences the likelihood of seeking medical treatment, and we found parents of children with enuresis have markedly different beliefs regarding bedwetting than those of physicians. Because achieving remission for PNE requires parents and their child to actively participate in treatment, assessing their expectancy of success and their beliefs will allow clinicians to adjust treatment goals as necessary. When treating PNE, guidelines consistently recommend incorporating bed alarms as part of the therapy. However, through interviewing parents and treating their children, we found parents preferred medications or other behavioral strategies, such as limiting water intake, because of their convenience. Many parents would complain bed alarms woke them up instead of their child, and they would soon give up on bed alarms. Part of assessing their beliefs includes assessing their confidence in their child being able to wake up to alarms and to persist with treatment. Understanding how they manage and approach setbacks will also determine the treatment modality suited for their child. In this review paper, we detailed our experiences interviewing parents and treating their child with NE with urodynamics and medications at the Changhua Christian Hospital in Taiwan.
\end{abstract}

Keywords: Taiwan, review, nocturnal enuresis, perception, behavior, treatment

\section{Introduction}

Nocturnal enuresis (NE) or bedwetting, is a common childhood disorder in which episodes of urinary incontinence occur during sleep. The cause of NE is complex and often multifactorial. Most studies classify NE as primary (PNE) when bladder control has never been attained, with secondary nocturnal enuresis (SNE) clinically diagnosed when incontinence reoccurs after achieving 6 months of dryness. ${ }^{1}$ It affects the social life of a child, and according to a survey, ${ }^{2}$ children with enuresis described bedwetting as the third most disruptive to their lives ranked only after divorce and parental conflict. Because parents and their children rarely find a clear underlying cause of bedwetting, they often respond to it with resignation, frustration, and anger, ${ }^{3}$ eventually leading them to discontinue proven and effective
Correspondence: Thomson T Tai Department of Surgery, Creighton University, 260I E Roosevelt St, Phoenix, AZ, 85004, USA

Tel +l 3153278659

Email ttail@luc.edu 
treatment methods, such as bed alarms. ${ }^{4,5}$ Because intolerance of $\mathrm{NE}$ is one factor leading parents to discontinue treatment, understanding the factors influencing parents' attitude to bedwetting is beneficial for coordinating a comprehensive treatment plan. ${ }^{6,7}$

Society and parents commonly expect children to achieve urinary continence by age six. This expectation increases as children get older. If they do not achieve continence, they are stigmatized, which can lead to low self-esteem and behavioral problems. ${ }^{8-10}$ After age ten, children with NE risked increased social maladjustment among their peers. ${ }^{11}$ Chang et $\mathrm{al}^{12}$ found children with PNE struggled more academically and socially, and their parents experienced and exhibited more parenting stress. Older children also reported more familial difficulties and expressed doubts about their appearance as they progressed through puberty. ${ }^{13}$ In Asian societies, parents are more likely to invest greater attention into parenting their older child, which influenced their approach toward bedwetting and subsequently treatment choice. ${ }^{13-15}$

Many treatment strategies for PNE exist. Common behavioral strategies include limiting fluid intake, timed voiding, and bed alarms. Common medications include desmopressin, imipramine, and oxybutynin. Electrotherapy, such as transcutaneous para-sacral electrical nerve stimulation and functional magnetic stimulation, has also been used with some success. For instance, a randomized clinical trial found that compared to standard behavioral therapy, transcutaneous electrical stimulation decreased wet nights 30 to $50 \%$ more in children with PNE. ${ }^{16}$ With so many choices available, how parents perceive bedwetting influences how they approach treatment. For instance, because of cultural norms in Taiwan and Chinese culture, parents were more likely to seek treatment for their first-born child. ${ }^{15}$ Almost half of parents we interviewed were unaware that specific therapies exist. Furthermore, in households where parents perceived bedwetting to be a behavioral problem, financial constraints were linked to an increased risk of domestic violence. ${ }^{17}$ Many parents also rarely see substantial or sustained improvement in their child's bedwetting problem, leading to frustration and ambivalence. ${ }^{15,18}$

In our experience, clinicians in Taiwan usually treat PNE with either desmopressin or imipramine as per Taiwan's treatment guidelines. ${ }^{19}$ Although studies have encouraged bed alarms as first-line because of their efficacy, ${ }^{20-22}$ we found parents either prefer Western medicine, traditional Chinese medicine, or homeopathic remedies. While traditional Chinese medicine can be effective, its dosage and approach towards diseases are unstandardized, and many patients who took Chinese medicine or homeopathic remedies did not see improvement in their symptoms.

In this review paper, we summarized and commented on studies pertaining to parental perceptions and the factors affecting thereof in influencing parents' treatment choice for PNE. We provided our experience obtained through interviewing, surveying, and treating children with NE at the Changhua Christian Hospital in Changhua City, Taiwan. We provided an in-depth understanding of the differences in perception between parents and their child, which affect treatment strategies, family dynamics, and the mental well-being of the child. Because family involvement is critical in any treatment plan, we believe healthcare practitioners should strive to understand how parents manage and approach bedwetting. We also discussed our experience with using urodynamics and common medications in the management of PNE while examining the factors influencing parents to seek medical treatment.

\section{Methods}

Primary nocturnal enuresis is a frequent childhood condition that clinicians and investigators alike have incorporated medical and behavioral interventions to treat. However, successful management requires an understanding in parents' and their children's perspectives. To better understand how this process occurs, we searched the PubMed database using the following keywords: nocturnal enuresis, treatment, behavior, urodynamics, epidemiology, and perception. We then evaluated and ranked each article based on their relevance to our topic review. Our topic review was structured around studies we have previous conducted. Emphasis was given to articles with the highest rank.

\section{Epidemiology, Pathogenesis, and Standard Treatments}

We defined nocturnal enuresis as urinary incontinence during sleep in children older than age five, following the International Continence Society. ${ }^{23}$ Primary nocturnal enuresis occurs when nighttime dryness has never been obtained for at least 6 months. Enuresis can be further separated into monosymptomatic or nonmonosymptomatic based on the presence of lower urinary 
tract symptoms or bladder dysfunction. The prevalence of $\mathrm{NE}$ at 7 years of age is approximately $15-22 \%$ and $7-15 \%$ of male and female children, respectively. This percentage reduces to less than $1 \%$ at age $18 .^{4,24-27}$ In Taiwan, the prevalence of bedwetting in children is approximately $8 \%$, a statistic like those of other countries, showing that NE is a medical disorder affecting children worldwide. ${ }^{28}$

The multifactorial nature of NE makes it difficult to treat. Common risk factors include underlying genetic predisposition, excessive urine production, developmental delays, difficulty awakening, male sex, fecal incontinence and constipation, and low socioeconomic status. ${ }^{28-30}$ Von Gontard et $\mathrm{al}^{31}$ demonstrated genes $8 \mathrm{q}, 12 \mathrm{q}$, and $13 \mathrm{q}$ predisposed children to developing $\mathrm{NE},{ }^{31}$ making family history a risk factor for developing NE. In addition, NE is associated with psychological disorders, and ADHD is present in as much as $20 \%$ of children with NE. ${ }^{32}$ Children with underlying pathologies have different remission rates, and long-term follow-up is often necessary.

Traditionally, clinicians treat children with PNE with both behavioral modifications and medications. Bed alarm is effective and recommended, although time constraints and inconvenience limit its utility. Thus, many parents prefer combining behavioral modifications such as limiting water intake with taking medications. Multiple efficacy studies estimated $30 \%$ of children achieved remission with desmopressin and reduced an average of one bedwetting episode per week. ${ }^{33}$ Despite its efficacy, only $10 \%$ remained continent at one year. ${ }^{34,35}$ Children who took imipramine, a second-line medication, showed 10 to $75 \%$ response rate, with similar relapse rates with those taking desmopressin. ${ }^{36,37}$ While both are similarly effective, most clinicians disfavor imipramine because of the risk of cardiac toxicity and water intoxication. These effects, however, rarely occur when treating PNE, as the therapeutic dose is much lower than that used for treating depression.

\section{Parents' Perception and Understanding of Nocturnal Enuresis and Their Influence on Treatment}

As PNE is a common childhood problem, parents are naturally concerned about its potential effects on their child's development. Some are more concerned about disease progression and its underlying pathophysiology, but many are concerned about PNE affecting their child's mental well-being and social development. For example, in Korea, parents of younger children with PNE were more concerned about disease progression, while parents of older children were more concerned about interpersonal relationships. ${ }^{38}$ Like Korean parents, parents in Taiwan often express concerns regarding the progression of PNE and its social implications. To explore how this may affect their decision to seek medical treatment, we recruited 93 children with PNE and investigated their parents' knowledge of and attitude toward their children's bedwetting. ${ }^{15}$ We categorized the parents' attitude toward bedwetting into three groups: 1) positive, 2) negative, and 3) ambivalence. The results showed angry and frustrated parents $(n=40,43 \%)$ were more likely to punish their child and to believe that punishment worked as a negative reinforcement strategy, although only $12 \%$ adopted punishment as a valid method. In contrast, parents $(n=31,34 \%)$ who approached bedwetting positively were more likely to encourage or comfort their children. ${ }^{15}$

Concerningly, child punishment is relatively common around the world, despite evidence showing that PNE is a complex medical disorder and not simply a behavioral problem. From our view, there are two major determinants: 1) lack of understanding and 2) cultural norms. ${ }^{24,39-41}$ Parents would adopt behavioral strategies such as limiting water intake, encouraging scheduled voiding, or urinating prior to bedtime, all strategies worth trying. ${ }^{39}$ But because many parents did not realize what healthcare practitioners could offer, many did not seek attention $^{39,42,43}$ In a study investigating the prevalence of PNE in Turkey, the authors found most children were left untreated as their parents were indifferent to bedwetting. ${ }^{41}$ Similarly, Yeung et al ${ }^{44}$ found Hong Kong's low prevalence rate of 3 to $4 \%$ was most likely attributed to parent indifference. In South Africa, Fockema et al found only $28 \%$ of children with PNE were treated with some form of intervention, and only $14 \%$ sought medical attention. ${ }^{39}$ About $40 \%$ of parents surveyed would not seek medical attention no matter what, although this figure was lower than Turkey's $87 \%$ and Malaysia's 75\%. In these scenarios, we found it effective to help parents understand the pathophysiology behind PNE and its disease progression to form effective coping strategies.

Regarding cultural norms, different cultures have varying beliefs and norms regarding acceptable parenting practices and childhood behavior. The variations in childrearing practices mean there is no consensus on optimal childcare or abuse. ${ }^{45}$ In Turkey, parents commonly punished their children, as Turkish mothers believed physical 
punishment benefitted their children. ${ }^{42,43,46}$ In Japan, history and physical examination documented child neglect and physical and sexual abuse. ${ }^{47}$ A Brazilian study reported that about half of the children with PNE experienced physical punishment without contact and the other half with contact. ${ }^{17}$ The authors concluded, in conjunction with other studies, that parents with low educational level were more likely to resort to punishment and less likely to seek medical attention. ${ }^{15,27,48}$ Children in low-income families were also more likely to experience domestic violence. In contrast, in a well-developed region in Istanbul, parents understood most bedwetting cases resolve spontaneously while being aware of the potential negative impact on mental wellbeing, and they sought help accordingly. $^{49}$

We also studied the impact of parents' attitudes regarding PNE on treatment outcomes. We found most parents, despite trying multiple treatment modalities, often perceived no substantial improvement in their child's disease progress. $^{15}$ This explained why many parents we interviewed were frustrated and considered enuresis to be hopeless. Because parental intolerance and annoyance negatively affect treatment success, working to understand their views and tailoring specific treatment strategies can be very effective. $5,38,50$

In Taiwan, most parents do not use bed alarms as they are time and resource intensive. They prefer strategies such as decreasing liquid intake, using diapers, or administering medications. ${ }^{15}$ We also observed parents who actively sought medical attention were more likely to incorporate Western medications into their treatment plan. In East Asian countries such as China, Hong Kong, and Taiwan, many families also use Chinese and herbal medicine, homeopathic remedies, or folklore therapies for treating illnesses. Many of them harbor traditional beliefs regarding the human body. Using traditional therapy is also more prevalent in households with elderly family members who strongly influence the treatment choice, and this may lead to slower remission or persistence.

Although there are many treatment options, most of them require strict compliance, and studies have found as high as 30 to $40 \%$ noncompliance rate with medications. Many parents also gave up bed alarms soon after despite its proven long-term efficacy. ${ }^{51-53}$ As children grow, some children and their parents also outright refused treatment, presumably because of annoyance. ${ }^{54}$ When approaching a family coping with PNE, after a thorough workup for organic causes, we strive to understand the parents' and their children's overall outlook toward bedwetting. Demographic factors such as socioeconomic status, parental educational level, and the child's age affect how parents perceive bedwetting and consequently their management strategy. Understanding these will go a long way in establishing a close and understanding relationship with families which improves communication and increases the likelihood of remission.

\section{How Do Differences in Perception Between Parents and Their Children Influence Enuresis Management?}

Nocturnal Enuresis is associated with psychosocial problems, especially in children. ${ }^{27,55,56}$ Most studies found bedwetting had a detrimental impact on dissociated behavior and social skills, although some had mixed findings. ${ }^{13}$ However, most experts concluded that after age ten, coping with NE significantly increases the risk of social maladjustment and mental disorders such as social anxiety. ${ }^{13,57}$ Behavioral problems and mental wellbeing are subjective and difficult to quantify, and most studies focused either on the caregivers' or the child's perspective. But few elaborated on the differences or similarities, with some attempting to understand how the differences between these two contrasting perspectives toward bedwetting influence treatment. Here we reviewed the literature and explored the following questions: 1) what was the parents' and their child's overall outlook on enuresis? 2) what were the factors affecting their attitudes? 3) what were the effects of these factors on their daily lives, and 4) how can we as clinicians use this information to better ensure treatment success?

Active family engagement is critical in the treatment of enuresis. Many studies, including ours, have focused on how parents approached their child's bedwetting, since treating PNE requires a combination of behavioral intervention and compliance to a strict medication regimen. ${ }^{58,59}$ For instance, Hascicek et al ${ }^{60}$ demonstrated in a prospective clinical trial that simply implementing a written checklist with clear behavioral instructions improved compliance rates from $40-60 \%$ to $70-80 \%$, along with a significant decrease in the number of wet nights. Parents who were instructed to return empty pill boxes also demonstrated similar compliance rates as parents who were given the checklist, although medication treatment were superior in treating NE. Other studies 
focused more on objective measures such as behavior, academic performance, and social interactions. ${ }^{61,62}$ From our experience discussing with parents their treatment goals, we noticed their decisions were influenced by three major determinants: 1) their beliefs regarding their child's ability to achieve dryness, 2) the negative social and emotional consequences, and 3) the severity of enuresis.

The presence and severity of social and psychological difficulties influence the likelihood of achieving remission. Interestingly, parents of children with PNE were more likely to complain their children had psychological problems, despite the children themselves denying such problems. ${ }^{13}$ Several studies also failed to find differences in behavior between children with PNE and their agematched peers. ${ }^{63,64}$ Three possibilities worth considering: 1) the children were in denial to preserve their selfesteem, 2) the severity of enuresis, and 3) the age of the child. Burns ${ }^{65}$ proposed that people act according to their own desires, which are then validated by their own selfimage and expectation, resulting in a self-fulfilling prophecy. For instance, learned helplessness is welldocumented in situations where people are subjected repeatedly to aversive conditions, leading to them "learning" that whatever they do is futile. In cases of repeated bedwetting, many children act powerless due to shame and the misunderstanding that they are solely responsible for bedwetting. ${ }^{66,67}$ They give up easily because they assume any successes are coincidental while setbacks confirm their belief. They do not comply with treatment long enough to see results, reinforcing their perceived helplessness. ${ }^{54}$ Their parents then interpret their behavior as indifference, which leads to arguments and possibly punishments. Both parties become mired in this cycle of helplessness.

This cycle of helplessness has detrimental effects on emotional growth, especially when we also consider the severity of enuresis and the child's age. As enuresis increased in severity, emotional outbursts and behavioral misconducts became more often. ${ }^{13,67}$ They also had difficulties communicating with their family and shied away from help, reinforcing their sense of helplessness. One way to counter this cycle of learned helplessness is through behavioral interventions such as cognitivebehavioral therapy and encouragement to instill greater self-confidence with the eventual goal of increasing their expectancy of success. ${ }^{68}$
In addition, as children mature, their appearances and the way they view themselves and others change. Bedwetting negatively affects this process during a period where adolescents compare themselves against each other and seek validation for their accomplishments. Previously, when we interviewed adolescents, a significant number denied behavioral or mental disorders, but on their questionnaires, they complained of increased family and emotional difficulties resulting from coping with bedwetting as they progressed through puberty. In contrast, their parents reported no discernible difference. ${ }^{13}$ The parents' perception that their child had become apathetic to bedwetting likely explained the discrepancy. By understanding this discrepancy and assessing parents and their child for readiness to engage in treatment, we can tailor medical advice and treatment strategies based on their financial and social resources.

\section{What are Important Risk Factors to Remember When Treating Children with PNE?}

The challenge faced by clinicians when treating PNE is identifying the subset of children likely to achieve spontaneous remission versus the children who would likely need more intensive management. One way to identify these factors is through longitudinal studies. Here in this section, we reviewed longitudinal studies on PNE which had investigated remission rates, risk factors, and comorbidities affecting enuretic children. We also provided a framework for helping to understand the changes these children went through and how this factored in formulating a treatment plan.

Clinicians have identified several important factors associated with PNE remission. Common factors include age, family and social stress, severity of enuresis, and sleep quality. In a 10-year follow-up study, Ferrara et $\mathrm{al}^{3}$ found remission rates increased with age regardless of whether the child was treated. In a three-year period, approximately $70 \%$ and $63 \%$ of treated and untreated children achieved remission, increasing to $86 \%$ and $75 \%$ at ten years. Since most studies employed a cross-sectional design, questions pertaining to how family tension and intra-family conflicts affect PNE remission rates were incompletely answered. To answer these questions, Fergusson et $\mathrm{al}^{57}$ followed children with PNE for 15 years and discovered that even after controlling for emotional maturity, IQ, and family conflict, children older than 
age ten exhibited more conduct issues, attention deficit behaviors, and social anxiety. This study suggested that while stressors at home contributed negatively to remission rates, bedwetting itself also acted as a stressor after age ten.

A 6-year follow-up study also found that age and remission rates correlated with one another. ${ }^{69}$ Approximately $97 \%$ of boys and girls achieved remission within eight years, although the authors defined PNE as night bedwetting at least weekly in children older than age eight. Supporting these findings, we also found that after 5.5 years, the overall remission rate was about $93 \%$ in Changhua, Taiwan, with girls having a slightly higher remission rate. ${ }^{14}$ About $7 \%$ of boys still experience bedwetting, compared to $6.5 \%$ of girls. Overall, most studies found girls have a higher likelihood to achieve dryness. Our study showed girls were $23 \%$ more likely to achieve remission. ${ }^{14}$ Similarly, in a sample of 1176 children, Swithinbank et al recorded a prevalence of $4.7 \%$ at age 11 , which decreases to $1.1 \%$ at age 15 . Primary Nocturnal Enuresis was also more prevalent for boys in both age groups. ${ }^{70}$ In Sweden, a study reported a prevalence of $0.7 \%$ in males and $0.6 \%$ in females at age $17 .^{71} \mathrm{In}$ China, Wen et $\mathrm{al}^{5}$ also reported a similar prevalence rate, with boys having a slightly higher rate. All these studies showed male gender as a risk factor. While we considered achieving remission as the goal, it is still important to keep in mind that many adolescents can continue to experience other urinary tract disorders such as urinary urgency and nocturia. $^{72}$

Another important factor to consider is the severity of bedwetting. Children with severe bedwetting, especially having three more wet nights per week, are at greater risk for persistent PNE. Studies have offered several plausible explanations. Yeung et $\mathrm{al}^{73}$ described that abnormal bladder functioning, including decreased capacity and detrusor hyperactivity, may be the culprit for refractory NE. An MRI study by Wang et $\mathrm{al}^{74}$ demonstrated children with PNE showed increased activity in the supplementary motor area and the medial prefrontal cortex regions, which may explain the increased bladder activity that leads to urinary incontinence. In our experience, parents of children with more severe bedwetting were also more likely to consult physicians and to participate in treatment plans. They also reported more anxiety regarding their child's development and disease progression. ${ }^{14,15}$

Traditionally, parents of children with PNE also complained about having to shake their children vigorously to wake them up. ${ }^{28}$ Clinicians referred to these children as "deep sleepers," a factor that correlated positively with the severity of PNE. Lettgen hypothesized these children may have lower vasopressin release when asleep, leading to bedwetting. ${ }^{75}$ Supporting this hypothesis was an observation made by Butler et al, where approximately $58 \%$ of children with severe PNE experienced bedwetting immediately after falling asleep, but children with mild PNE did not. ${ }^{25}$ Most children who responded to desmopressin also voided within one hour of falling asleep. ${ }^{76}$ Often, parents would complain that their child would seemingly still be asleep even after being led to the restroom. Tai et $\mathrm{al}^{28}$ collaborated these findings. The authors showed the timing of bedwetting correlated with enuresis severity, and older children with PNE were likely to be deep sleepers. What these studies had in common was that all these children have difficulty responding to voiding stimuli.

However, the pathogenesis of PNE is unclear, with inconsistencies in the studies we reviewed. Was the voiding stimulus insufficient for sleep arousal? Or Was bladder hyperactivity the culprit? Sleep studies investigating brain electrical activity in children with PNE showed a higher incidence of delta waves, or slow brainwaves, although these were nonspecific findings. ${ }^{77}$ Researchers also noted an increased hyper-ventilatory response, a sign of brain immaturity, in children experiencing either primary or secondary enuresis. ${ }^{78}$ Wolfish et al noted older children with PNE were harder to arouse compared to their peers and frequently urinated in the first few hours of sleep rather than the last few hours. The authors suggested delayed arousal threshold was likely the cause, resulting from delayed brain maturation. ${ }^{79}$ A recent prospective controlled trial found that when groups with and without NE were compared, children with NE were significantly more likely to present with lower urinary tract symptoms. ${ }^{80}$ They also had significantly lower rates of dryness and responded more poorly to enuresis treatment. Taken together, the current evidence suggested that PNE is likely a complex, multifactorial disorder.

In our experience, parents preferred medications and simple behavioral interventions over bed alarms. We found that while bed alarms are effective, parents would complain their children slept right through the alarm. Delayed arousal threshold may play a role, and parents would give up bed alarms soon after their implementation. Other studies also reported compliance rates because of their inconvenience. ${ }^{53,81}$ Older children also reported lower compliance rates with alarms. ${ }^{82}$ Part of the problem may 
be their desire for an immediate solution, and their tendency to give up because of perceived helplessness. While hard to predict on an individual level, around 5-10\% of children with PNE will continue to wet their beds through adolescence and into adulthood. ${ }^{82}$ If clinicians decide to implement bed alarm therapies as a treatment strategy in this age group, it may be worthwhile to assess both the parents and their children's understanding of bed alarms and expectancy of success.

\section{How Physician and Parental Perception on Medications Influence Management}

Current treatment strategies primarily focus on bed alarms and desmopressin. Other treatment options are available, including but not limited to tricyclic antidepressants (ie, imipramine), anticholinergics (ie, oxybutynin), and simple behavioral interventions such as limiting water intake. Consensus guidelines recommend alarm as first-line or combined with desmopressin. ${ }^{33}$ However, several studies have reported low remission rates for bed alarms because of compliance issues. Parents and their children with PNE often overestimated their compliance, regardless of treatment modality. ${ }^{51,52}$ The need for strict adherence to treatment and the inconvenience bed alarm causes may partially explain the difficulty in staying compliant. For instance, Walle et $\mathrm{al}^{51}$ found parents commonly overestimated their children's compliance. Voiding diaries were often incomplete, and children did not always take desmopressin tablets as scheduled, which negatively affected remission rates. In Taiwan, patients favor desmopressin, imipramine, or other medications over bed alarms because of convenience. Here we reviewed studies on the use of desmopressin and bed alarms, and how physician and parental perception of bedwetting influenced their use.

Optimal management of PNE should include bed alarms. The intended purpose is to reduce the maximum voided volume and strengthen the association between voiding stimulus and awakening. However, parents find alarms expensive and inconvenient, and the results are not as immediate. ${ }^{81}$ In addition, alarms may not work as effectively in deep sleepers. ${ }^{28,82}$ Many parents in Taiwan would complain that the alarm regularly woke them up instead of their child. Bed alarms also take several weeks before the child will wake up to it. Onol et $\mathrm{al}^{53}$ found that while at 12 months, success rates (defined as $90 \%$ reduction in wet nights per month) were similar between children treated with desmopressin and children treated with alarm, long-term success rate was significantly higher with desmopressin (68.8\% v. 46.2\%). Parents who consulted us for severe enuresis were also more likely to feel ambivalent or intolerant, ${ }^{15}$ and this may negatively affect remission rates, as they were more likely to discontinue medical therapy, such as bed alarms. ${ }^{6,7}$ As healthcare costs continue to increase and physicians face greater time constraints, fewer physicians had the time to understand the needs of the parents and who may benefit from bed alarms. Consequently, many preferred to prescribe medications for immediate results while advising parents to implement simple behavioral interventions such as limiting water intake or star charts.

Differences in perception between parents and physicians also lead to different management strategies. Ju et $\mathrm{al}^{38}$ observed that in Korea, while parents of children with PNE worried more about disease progression, physicians were concerned more with interpersonal relationships, although low self-esteem was a concern among both groups. Regarding treatment preferences, the authors hypothesized parents would prefer convenient and fastacting treatment modalities such as desmopressin, while physicians would prefer treatments with higher long-term success rates. Instead, they found the opposite- physicians preferred "quick fixes" whereas parents preferred treatments with low relapse rates. Interestingly, when asked about their ideal treatments, physicians were significantly more likely to incorporate alarm therapy as part of the treatment plan, while parents had no strong therapeutic preference. Taken together, these findings suggested patients were more worried about the long-term complications of enuresis. Morison et $\mathrm{al}^{83}$ found in many situations, parents felt physicians had little to offer them, although they appreciated their advice. The lack of assessing parents their preferences or understanding can lead to passive involvement in their child's treatment. Physicians can mitigate these discrepancies in perception with a more thorough assessment of parents' expectancy of treatment outcome and filling the gaps. This will help parents and their children to actively manage PNE, increasing the overall success rate.

In Taiwan, in contrast to other countries, imipramine and desmopressin are both recommended as first-line medications for treating PNE. The primary concern is imipramine's side effect profile, which includes cardiac toxicity and water intoxication. However, these serious effects are only of concern when taking imipramine at the dose used 
to treat major depression, and the dose used to treat imipramine is 2-3 times lower. Many research evaluating the effects of desmopressin and imipramine on bedwetting had comparable results. ${ }^{1,33,84}$ Some other studies reported desmopressin worked better short-term, while both drugs worked equally well long term ${ }^{34}$ Other studies found greater efficacy if desmopressin was combined with oxybutynin than standalone desmopressin, ${ }^{85}$ while others found intranasal desmopressin to be more superior. ${ }^{86}$ In contrast, we found no significant differences in remission rates between desmopressin and imipramine at three months, with similar relapse rates during a 3-month posttreatment follow up (36.6 to $48.8 \%$ ). While no children treated with desmopressin reported side effects, about 5\% of children treated with imipramine reported either dry mouth, constipation, or hand tremor. ${ }^{87}$ At the time of the study, we could treat 16 children with imipramine before one child with desmopressin, highlighting the costeffectiveness of imipramine. Following a thorough review of the literature, we did not find any reports of children treated with imipramine experiencing serious side effects at the dose used for NE.

\section{Is Urodynamics Necessary for PNE?}

When assessing a child with urinary complaints, the primary evaluation includes a thorough history and physical and urinalysis. If symptoms suggest PNE, guidelines strongly recommend keeping a voiding diary along with assessing for other probable causes, such as developmental delay and sleep-related disorders. Hypothetically, by reducing the stimulus (ie, water), strengthening the pathways between sleep arousal and bladder fullness through bed alarms, and decreasing the urine output with medications, children with PNE should achieve partial or full remission. This is sometimes not the case, and children with significant underlying bladder dysfunction may only present with primary enuresis with or without response to desmopressin. ${ }^{73}$ Combined with an increase in nocturnal urine production, nocturnal polyuria subsequently follows. In refractory cases, urodynamics is necessary, and dysfunctional bladder has been found in children with PNE.

When standard treatments fail, primary care physicians refer patients to specialists and for further clinical testing, including urodynamic studies. Studies have found that daytime maximal voided volume (DMVV) predicted relatively well a child's response to desmopressin. ${ }^{88,89}$ This was used as a surrogate for maximal voided volume (MVV), as the latter is highly predictive of response to desmopressin. However, these two volumes may differ in children with PNE because of bladder dysfunction at night. Borg et $\mathrm{al}^{90}$ demonstrated that a significant number of children with primary monosymptomatic enuresis who had normal DMVV experienced reduced nighttime voided volume (NVV). Of those, only $11 \%$ who frequently experienced reduced NVV responded to desmopressin, compared to $40-45 \%$ of children who did not or infrequently experienced reduced NVV. These results showed that recording daytime voiding volumes may not differentiate patients who would respond to desmopressin and patients who would not.

While voiding journals are helpful, in our experience, parents found voiding diary troublesome. In Taiwan, compliance is low because many households have both parents working throughout the day, and their child participates in after school activities. This makes it difficult to find time to record daytime voiding volumes. Parents also expressed difficulty in estimating nocturnal urine output. Lastly, estimating bladder capacity, which predicts response to desmopressin, from voiding journals can be difficult and inaccurate. $^{91,92}$ In one of our unpublished studies, we found children who did not respond or responded partially to desmopressin had smaller cytometric capacity, correlating the findings of other studies. ${ }^{90,92,93}$ Children with smaller bladder capacities were also likely to have overactive bladder (OAB), a condition that clinicians should concurrently treat with anticholinergics. Clinicians should also assess for and treat constipation. Im et $\mathrm{al}^{94}$ investigated 111 children with $\mathrm{OAB}$ and primary enuresis and suggested that for better outcomes, clinicians should ideally address fecal impaction or severe constipation first.

Our unpublished data also found no significant differences in voided volume, maximum flow rate, and bladder capacity between full and partial responders among children with small bladders or OAB. This finding implied other factors are at play, including but not limited to environmental stress, behavioral problems, and psychological disorders. Indeed, a ROC curve showed a cut-off bladder capacity of 140cc; if a child's bladder capacity was greater than $140 \mathrm{cc}$, there was a $63 \%$ probability of a complete response to desmopressin. Conversely, if a child's bladder capacity was less than that, there was a $60 \%$ probability of not responding or only partially responding to desmopressin. Because bedside ultrasound can readily and accurately estimate bladder filling capacity, ${ }^{95}$ documenting a child's bladder capacity during subsequent physical exams can be just 
as helpful as a voiding journal. Clinicians have successfully used imipramine and oxybutynin to treat these children with PNE presenting with small bladders as well as children with normal DMVV but abnormal nocturnal bladder functioning. ${ }^{96-98}$

\section{Conclusion}

Treating PNE and excluding other potential causes can be challenging for the patient, the family, and the clinician. Because treating enuresis requires active engagement and the willingness to achieve dryness, assessing attitudes toward bedwetting is helpful in predicting behavior in engaging and complying with treatment. We illustrated in our paper the importance of assessing parents their beliefs and ideas about bedwetting, especially how they approach the negative implications of bedwetting. In many cases, their ideas contrasted those of healthcare professionals, and bridging this gap can help prevent failures in treatment. Understanding the environment in which the therapy takes place allows us to consider the financial and social realities of the family. While treatment guidelines consistently recommend bed alarms for primary enuresis and to add on desmopressin if desired results are not achieved, the reality is that many parents and their children find it difficult to persist with alarm treatment. Assessing their attitudes and expectancy of success will go a long way in improving the overall treatment experience and success rate.

One of the challenges in studying nocturnal enuresis is the disparity in the definitions of enuresis and how interventions are measured. Because enuresis is partially behavioral and partially physiologic, quantifying the behavioral interventions is challenging. Our review article is thus limited in objectively analyzing how different parenting styles or behavioral interventions impact the development or management of enuresis. To the best of our knowledge, there have not been meta-analytic studies quantifying or assessing the environment variables that influence the development or treatment of enuresis. As a result, some questions remain. How can we better assess for environmental factors that contribute to the development and persistence of enuresis? Is cognitive-behavioral therapy and biofeedback therapy valid adjunct therapies? Importantly, how do we as clinicians identify complex cases of PNE earlier to form more aggressive treatment plans? These questions will form suitable inquiries for further study.

\section{Abbreviations}

NE, nocturnal enuresis; PNE, primary nocturnal enuresis; SNE, secondary nocturnal enuresis; DMVV, daily maximal voided volume; NVV, nocturnal voided volume; OAB, overactive bladder; ROC, receiving operating characteristic curve.

\section{Disclosure}

The authors report no conflicts of interest in this work.

\section{References}

1. Robson WLM. Evaluation and management of enuresis. $N$ Engl $J$ Med. 2009;360(14):1429-1436. doi:10.1056/NEJMcp0808009

2. van Tijen Nm, Messer AP, Namdar Z. Perceived stress of nocturnal enuresis in childhood. Br J Urol. 1998;81:98-99. doi:10.1046/j.1464410x.1998.00018.x

3. Ferrara P, de Angelis MC, Caporale O, et al. Possible impact of comorbid conditions on the persistence of nocturnal enuresis: results of a long-term follow-up study. Urol J. 2014;11(4):1777.

4. Kajiwara M, Inoue K, Usui A, Kurihara M, Usui T. The micturition habits and prevalence of daytime urinary incontinence in Japanese primary school children. J Urol. 2004;171(1):403-407. doi:10.1097/ 01.ju.0000101907.87169.06

5. Wen JG, Wang QW, Chen Y, Wen JJ, Liu K. An epidemiological study of primary nocturnal enuresis in Chinese children and adolescents. Eur Urol. 2006;49(6):1107-1113. doi:10.1016/j. eururo.2005.11.011

6. Evans GD, Radunovich HL. Bedwetting. EDIS. 2006;2006(15). Available from: https://scholar.google.com/scholar?hl=en\&as_sdt= $0 \% 2 \mathrm{C} 3 \& \mathrm{q}=$ Evans $+\mathrm{GD} \% 2 \mathrm{C}+$ Radunovich $+\mathrm{HL} .+$ Bedwetting. + EDIS. $+2006 \% 3 \mathrm{~B} 2006 \% 2815 \% 29 \& \mathrm{btnG}=$. Accessed August 30, 2021.

7. Utler RJ, Brewin CR, Forsythe WI. A comparison of two approaches to the treatment of nocturnal enuresis and the prediction of effectiveness using pre-treatment variables. $J$ Child Psychol Psychiatr. 1988;29(4):501-509. doi:10.1111/j.1469-7610.1988.tb00740.x

8. Butler R, Heron J. An exploration of children's views of bed-wetting at 9 years. Child Care Health Dev. 2008;34(1):65-70.

9. Coppola G, Costantini A, Gaita M, Saraulli D. Psychological correlates of enuresis: a case-control study on an Italian sample. Pediatr Nephrol. 2011;26(10):1829-1836. doi:10.1007/s00467011-1880-3

10. Joinson C, Heron J, Emond A, Butler R. Psychological problems in children with bedwetting and combined (day and night) wetting: a UK population-based study. $J$ Pediatr Psychol. 2007;32 (5):605-616. doi:10.1093/jpepsy/js1039

11. Schober JM, Lipman R, Haltigan JD, Kuhn PJ. The impact of monosymptomatic nocturnal enuresis on attachment parameters. Scand J Urol Nephrol. 2004;38(1):47-52. doi:10.1080/ 00365590310001665

12. Chang SSY, Ng CFN, Wong SN; Group HKCES. Behavioural problems in children and parenting stress associated with primary nocturnal enuresis in Hong Kong. Acta Paediatr. 2002;91(4):475-479. doi:10.1111/j.1651-2227.2002.tb01673.x

13. Tai TT, Tai BT, Chang Y, Huang K. Parents have different perceptions of bed-wetting than children from six to 15 years of age. Acta Paediatr. 2015;104(10):e466-e472. doi:10.1111/apa.13101

14. Tai BT, Tai TT, Chang Y-J, Huang K-H. Factors associated with remission of primary nocturnal enuresis and changes of parental perception towards management strategies: a follow-up study. J Pediatr Urol. 2017;13(1):44-e1. 
15. Tai TT, Tai BT, Chang Y-J, Huang K-H. Parental perception and factors associated with treatment strategies for primary nocturnal enuresis. J Pediatr Urol. 2017;13(3):272-e1.

16. Kajbafzadeh A-M, Sharifi-Rad L, Mozafarpour S, Ladi-Seyedian -S-S. Efficacy of transcutaneous interferential electrical stimulation in treatment of children with primary nocturnal enuresis: a randomized clinical trial. Pediatr Nephrol. 2015;30(7):1139-1145. doi:10.1007/s00467-014-3039-5

17. Sapi MC, Vasconcelos JS, Silva FG, Damião R, Silva EA. Assessment of domestic violence against children and adolescents with enuresis. J Pediatr (Rio J). 2009;85(5):433-437.

18. Butler R, McKenna S. Overcoming parental intolerance in childhood nocturnal enuresis: a survey of professional opinion. BJU Int. 2002;89(3):295-297. doi:10.1046/j.1464-4096.2001.01774.x

19. Yang SS, Chiou Y-H, Lin C-Y, et al. Treatment guideline of enuresis in Taiwan. Acta Paediatr Taiwan. 2001;42(5):271-277.

20. Glazener CMA, Evans JHC, Peto RE. Alarm interventions for nocturnal enuresis in children. Cochrane Database Syst Rev. 2005;(2): CD002911. doi:10.1002/14651858.CD002911.pub2

21. Houts AC, Berman JS, Abramson H. Effectiveness of psychological and pharmacological treatments for nocturnal enuresis. $J$ Consult Clin Psychol. 1994;62(4):737. doi:10.1037/0022-006X.62.4.737

22. Butler RJ, Holland P, Gasson S, Norfolk S, Houghton L, Penney M. Exploring potential mechanisms in alarm treatment for primary nocturnal enuresis. Scand J Urol Nephrol. 2007;41(5):407-413. doi:10.1080/00365590701571506

23. Nevéus T, von Gontard A, Hoebeke P, et al. The standardization of terminology of lower urinary tract function in children and adolescents: report from the Standardisation Committee of the International Children's Continence Society. J Urol. 2006;176(1):314-324. doi:10.1016/S0022-5347(06)00305-3

24. De S, Teixeira-Pinto A, Sewell JR, Caldwell PHY. Prevalence, patient and consultation characteristics of enuresis in Australian paediatric practice. J Paediatr Child Health. 2018;54(6):620-624. doi:10.1111/jpc. 13834

25. Butler RJ, Golding J, Northstone K, Team AS. Nocturnal enuresis at 7.5 years old: prevalence and analysis of clinical signs. BJU Int. 2005;96(3):404-410. doi:10.1111/j.1464-410X.2005.05640.x

26. Safarinejad MR. Prevalence of nocturnal enuresis, risk factors, associated familial factors and urinary pathology among school children in Iran. J Pediatr Urol. 2007;3(6):443-452. doi:10.1016/j.jpurol.2007.06.001

27. Mahmoodzadeh H, Amestejani M, Karamyar M, Nikibakhsh -A-A. Prevalence of nocturnal enuresis in school aged children: the role of personal and parents related socio-economic and educational factors. Iran J Pediatr. 2013;23(1):59.

28. Tai H, Chang Y, Chang SC, Chen G, Chang C, Chou M. The epidemiology and factors associated with nocturnal enuresis and its severity in primary school children in Taiwan. Acta Paediatr. 2007;96(2):242-245. doi:10.1111/j.1651-2227.2007.00025.x

29. Akashi S, Tomita K. The impact of a history of childhood nocturnal enuresis on adult nocturia and urgency. Acta Paediatr. 2014;103(9): e410-e415. doi:10.1111/apa.12694

30. Butler RJ, Holland P. The three systems: a conceptual way of understanding nocturnal enuresis. Scand J Urol Nephrol. 2000;34 (4):270-277. doi:10.1080/003655900750042022

31. von Gontard A, Schaumburg H, Hollmann E, Eiberg H, Rittig S. The genetics of enuresis: a review. J Urol. 2001;166(6):2438-2443. doi:10.1016/S0022-5347(05)65611-X

32. von Gontard A, Mauer-Mucke K, Plück J, Berner W, Lehmkuhl G. Clinical behavioral problems in day-and night-wetting children. Pediatr Nephrol. 1999;13(8):662-667. doi:10.1007/s004670050677

33. Neveus T, Eggert P, Evans J, et al. Evaluation of and treatment for monosymptomatic enuresis: a standardization document from the International Children's Continence Society. J Urol. 2010;183 (2):441-447. doi:10.1016/j.juro.2009.10.043

34. Johnson M. Nocturnal enuresis. Urol Nurs. 1998;18(4):259-275.
35. Monda JM, Husmann DA. Primary nocturnal enuresis: a comparison among observation, imipramine, desmopressin acetate and bed-wetting alarm systems. $J$ Urol. 1995;154(2):745-748. doi:10.1016/S0022-5347(01)67152-0

36. Glazener CMA, Grant A, Wallace SA. Treating nocturnal enuresis in children. Effect Health Care Bull. 2003;8(2):1-8.

37. Cendron M. Primary nocturnal enuresis: current. Am Fam Physician. 1999;59(5):1205.

38. Ju HT, Kang JH, Lee SD, et al. Parent and physician perspectives on the treatment of primary nocturnal enuresis in Korea. Korean J Urol. 2013;54(2):127. doi:10.4111/kju.2013.54.2.127

39. Fockema MW, Candy GP, Kruger D, Haffejee M. Enuresis in South African children: prevalence, associated factors and parental perception of treatment. BJU Int. 2012;110(11c):E1114-E1120. doi:10.1111/j.1464-410X.2012.11416.x

40. Doganer YC, Aydogan U, Ongel K, Sari O, Koc B, Saglam K. The prevalence and sociodemographic risk factors of enuresis nocturna among elementary school-age children. $J$ Fam Med Prim Care. 2015;4(1):39. doi:10.4103/2249-4863.152250

41. Sarici H, Telli O, Ozgur BC, Demirbas A, Ozgur S, Karagoz MA. Prevalence of nocturnal enuresis and its influence on quality of life in school-aged children. J Pediatr Urol. 2016;12(3):159-e1. doi:10.1016/j.jpurol.2015.11.011

42. Karaman MI, Koca O, Kucuk EV, Ozturk MI, Akyuz M. Methods and rates of punishment implemented by families to enuretic children in Turkey. Int Braz J Urol. 2013;39(3):402-407. doi:10.1590/S16775538.IBJU.2013.03.14

43. Can G, Topbas M, Okten A, Kizil M. Child abuse as a result of enuresis. Pediatr Int. 2004;46(1):64-66. doi:10.1111/j.1442200X.2004.01829.x

44. Yeung CK, Sreedhar B, Sihoe JDY, Sit FKY, Lau J. Differences in characteristics of nocturnal enuresis between children and adolescents: a critical appraisal from a large epidemiological study. BJU Int. 2006;97(5):1069-1073. doi:10.1111/j.1464-410X.2006.06074.x

45. Korbin JE. Cross-cultural perspectives and research directions for the 21st century. Child Abuse Negl. 1991;15:67-77. doi:10.1016/01452134(91)90010-B

46. Özkan KU, Garipardic M, Toktamis A, Karabiber H, Sahinkanat T. Enuresis prevalence and accompanying factors in schoolchildren: a questionnaire study from southeast Anatolia. Urol Int. 2004;73 (2):149-155. doi: $10.1159 / 000079696$

47. Nakamura Y. Child abuse and neglect in Japan. Pediatr Int. 2002;44 (5):580-581. doi:10.1046/j.1442-200X.2002.01641.x

48. Schlomer B, Rodriguez E, Weiss D, Copp H. Parental beliefs about nocturnal enuresis causes, treatments, and the need to seek professional medical care. J Pediatr Urol. 2013;9(6):1043-1048. doi:10.1016/j.jpurol.2013.02.013

49. Carman KB, Ceran O, Kaya C, Nuhoglu C, Karaman MI. Nocturnal enuresis in Turkey: prevalence and accompanying factors in different socioeconomic environments. Urol Int. 2008;80(4):362-366. doi: $10.1159 / 000132692$

50. Wada H, Kimura M, Tajima T, et al. Nocturnal enuresis and sleep disordered breathing in primary school children: potential implications. Pediatr Pulmonol. 2018;53(11):1541-1548. doi:10.1002/ppul.24156

51. Walle J, Rittig S, Bauer S, Eggert P, Marschall-Kehrel D, Tekgul S. Practical consensus guidelines for the management of enuresis. Eur J Pediatr. 2012;171(6):971-983. doi:10.1007/s00431-012-1687-7

52. van Herzeele C, Alova I, Evans J, et al. Poor compliance with primary nocturnal enuresis therapy may contribute to insufficient desmopressin response. $J$ Urol. 2009;182(4S):2045-2049. doi:10.1016/j.juro.2009.06.001

53. Önol FF, Guzel R, Tahra A, Kaya C, Boylu U. Comparison of long-term efficacy of desmopressin lyophilisate and enuretic alarm for monosymptomatic enuresis and assessment of predictive factors for success: a randomized prospective trial. J Urol. 2015;193 (2):655-661. doi:10.1016/j.juro.2014.08.088 
54. Nappo S, Del Gado R, Chiozza ML, Biraghi M, Ferrara P, Caione P. Nocturnal enuresis in the adolescent: a neglected problem. BJU Int. 2002;90(9):912-917. doi:10.1046/j.1464-410X.2002.03030.x

55. Wolfe-Christensen C, Veenstra AL, Kovacevic L, Elder JS, Lakshmanan Y. Psychosocial difficulties in children referred to pediatric urology: a closer look. Urology. 2012;80(4):907-913. doi:10.1016/j.urology.2012.04.077

56. Cederblad M, Nevéus T, Åhman A, Efraimsson EÖ, Sarkadi A. "Nobody asked us if we needed help": Swedish parents experiences of enuresis. J Pediatr Urol. 2014;10(1):74-79. doi:10.1016/j. jpurol.2013.06.006

57. Fergusson DM, Horwood LJ. Nocturnal enuresis and behavioral problems in adolescence: a 15-year longitudinal study. Pediatrics. 1995;95(2):243.

58. Durmaz O, Kemer S, Mutluer T, Bütün E. Psychiatric dimensions in mothers of children with primary nocturnal enuresis: a controlled study. J Pediatr Urol. 2017;13(1):62-e1. doi:10.1016/j.jpurol.2016. 08.016

59. de Bruyne E, van Hoecke E, van Gompel K, et al. Problem behavior, parental stress and enuresis. J Urol. 2009;182(4S):2015-2021. doi:10.1016/j.juro.2009.05.102

60. Hascicek AM, Kilinc MF, Yildiz Y, Yuceturk CN, Doluoglu OG. A new checklist method enhances treatment compliance and response of behavioural therapy for primary monosymptomatic nocturnal enuresis: a prospective randomised controlled trial. World J Urol. 2019;37 (6):1181-1187. doi:10.1007/s00345-018-2478-1

61. van Hoecke E, de Fruyt F, de Clercq B, Hoebeke P, Vande walle J. Internalizing and externalizing problem behavior in children with nocturnal and diurnal enuresis: a five-factor model perspective. J Pediatr Psychol. 2006;31(5):460-468. doi:10.1093/jpepsy/jsj037

62. Liu X, Sun Z, Uchiyama M, Li YAN, Okawa M. Attaining nocturnal urinary control, nocturnal enuresis, and behavioral problems in Chinese children aged 6 through 16 years. J Am Acad Child Adolesc Psychiatry. 2000;39(12):1557-1564. doi:10.1097/ 00004583-200012000-00020

63. Wagner WG, Smith D, Norris WR. The psychological adjustment of enuretic children: a comparison of two types. J Pediatr Psychol. 1988;13(1):33-38. doi:10.1093/jpepsy/13.1.33

64. Wille S, Anveden I. Social and behavioural perspectives in enuretics, former enuretics and non-enuretic controls. Acta Paediatr. 1995;84 (1):37-40. doi:10.1111/j.1651-2227.1995.tb13481.x

65. Burns RB. Essential Psychology. Springer Science \& Business Media; 2008

66. Hägglöf B, Andren O, Bergström E, Marklund L, Wendelius M. Selfesteem before and after treatment in children with nocturnal enuresis and urinary incontinence. Scand J Urol Nephrol Suppl. 1997;183:79-82.

67. Kanaheswari Y, Poulsaeman V, Chandran V. Self-esteem in 6-to 16year-olds with monosymptomatic nocturnal enuresis. J Paediatr Child Health. 2012;48(10):E178-E182. doi:10.1111/j.14401754.2012.02577.x

68. Morison MJ. Parents' and young people's attitudes towards bedwetting and their influence on behaviour, including readiness to engage in and persist with treatment. Br J Urol. 1998;81:56-66. doi:10.1046/ j.1464-410x.1998.00010.x

69. Moilanen I, Tirkkonen T, Järvelin M-R, et al. A follow-up of enuresis from childhood to adolescence. $B r \quad J$ Urol. 1998;81:94-97. doi:10.1046/j.1464-410x.1998.00017.x

70. Swithinbank LV, Brookes ST, Shepherd AM, Abrams P. The natural history of urinary symptoms during adolescence. $\mathrm{Br} J$ Urol. 1998;81:90-93. doi:10.1046/j.1464-410x.1998.00016.x

71. Hellström A, Hanson E, Hansson S, Hjälmäs K, Jodal U. Micturition habits and incontinence at age 17-reinvestigation of a cohort studied at age 7. $B r J$ Urol. 1995;76(2):231-234. doi:10.1111/j.1464410X.1995.tb07681.x
72. Goessaert A-S, Schoenaers B, Opdenakker O, Hoebeke P, Everaert K, Vande Walle J. Long-term followup of children with nocturnal enuresis: increased frequency of nocturia in adulthood. J Urol. 2014;191 (6):1866-1871. doi:10.1016/j.juro.2013.12.051

73. Yeung CK, Chiu HN, Sit FKY. Bladder dysfunction in children with refractory monosymptomatic primary nocturnal enuresis. $J$ Urol. 1999;162(3Part 2):1049-1054. doi:10.1016/S0022-5347(01)68062-5

74. Wang M, Zhang A, Zhang J, et al. Morphometric magnetic resonance imaging study in children with primary monosymptomatic nocturnal enuresis. Front Pediatr. 2018;6:103. doi:10.3389/ fped.2018.00103

75. Lettgen B. Differential diagnoses for nocturnal enuresis. Scand J Urol Nephrol Suppl. 1997;183:47-48.

76. Nevéus T, Stenberg A, Läckgren G, Tuvemo T, Hetta J. Sleep of children with enuresis: a polysomnographic study. Pediatrics. 1999;103(6):1193-1197. doi:10.1542/peds.103.6.1193

77. Kawauchi A, Imada N, Tanaka Y, Minami M, Watanabe H, Shirakawa S. Changes in the structure of sleep spindles and delta waves on electroencephalography in patients with nocturnal enuresis. Br J Urol. 1998;81:72-75. doi:10.1046/j.1464-410x.1998.00012.x

78. Kaada B, Retvedt A. Enuresis and hyperventilation response in the EEG. Dev Med Child Neurol. 1981;23(6):591-599. doi:10.1111/ j.1469-8749.1981.tb02040.x

79. Wolfish NM, Pivik RT, Busby KA. Elevated sleep arousal thresholds in enuretic boys: clinical implications. Acta Paediatr. 1997;86 (4):381-384. doi:10.1111/j.1651-2227.1997.tb09027.x

80. Yavuz A, Bayar G, Kilinc MF, Sariogullari U. The relationship between nocturnal enuresis and spina bifida Occulta: a prospective controlled trial. Urology. 2018;120:216-221. doi:10.1016/j. urology.2018.07.038

81. Jang WS, Cho JS, Kim JM, Hong CH. Application and treatment result of an enuresis alarm based on a questionnaire in children with enuresis. Korean $J$ Urol. 2008;49(8):745-752. doi:10.4111/ kju.2008.49.8.745

82. Vandersteen DR, Husmann DA. Treatment of primary nocturnal enuresis persisting into adulthood. J Urol. 1999;161(1):90-92. doi:10.1016/S0022-5347(01)62073-1

83. Morison MJ, Tappin D, Staines H. You feel helpless, that's exactly it': parents' and young people's control beliefs about bedwetting and the implications for practice. $J$ Adv Nurs. 2000;31(5):1216-1227. doi:10.1046/j.1365-2648.2000.01426.x

84. Seyfhashemi M, Ghorbani R, Zolfaghari A. Desmopressin, imipramine, and oxybutynin in the treatment of primary nocturnal enuresis: a randomized clinical trial. Iran Red Crescent Med J. 2015;17(7): e16174. doi:10.5812/ircmj.16174v2

85. Lee T, Suh HJ, Lee HJ, Lee JE. Comparison of effects of treatment of primary nocturnal enuresis with oxybutynin plus desmopressin, desmopressin alone or imipramine alone: a randomized controlled clinical trial. $J$ Urol. 2005;174(3):1084-1087. doi:10.1097/01. ju. 0000169160.84418 .15

86. Vertucci P, Lanzi C, Capece G, et al. Desmopressin and imipramine in the management of nocturnal enuresis: a multicentre study. $\mathrm{Br}$ J Clin Pract. 1997;51(1):27-31.

87. Tai TT, Tai BT, Chang Y-J, Huang K-H. Experience of medical treatment with desmopressin and imipramine in children with severe primary nocturnal enuresis in Taiwan. Res Rep Urol. 2019;11:283. doi:10.2147/RRU.S221443

88. Rushton HG, Belman AB, Zaontz MR, Skoog SJ, Sihelnik S. The influence of small functional bladder capacity and and other predictors on the response to desmopressin in the management of monosymptomatic nocturnal enuresis. J Urol. 1996;156(2S):651-655. doi:10.1016/S0022-5347(01)65775-6

89. Tauris LH, Kamperis K, Hagstroem S, Bower WF, Rittig S. Tailoring treatment of monosymptomatic nocturnal enuresis: the role of maximum voided capacity. J Urol. 2012;187(2):664-669. doi:10.1016/j. juro.2011.10.014 
90. Borg B, Kamperis K, Olsen LH, Rittig S. Evidence of reduced bladder capacity during nighttime in children with monosymptomatic nocturnal enuresis. J Pediatr Urol. 2018;14(2):160-e1. doi:10.1016/j. jpurol.2017.09.021

91. Cho WY, Kim SC, Kim S-O, et al. Can recording only the day-time voided volumes predict bladder capacity? Investig Clini Urol. 2018;59(3):194. doi:10.4111/icu.2018.59.3.194

92. Martínez-García R, Úbeda-sansano MI, Díez-Domingo J, PérezHoyos S, Gil-Salom M. It is time to abandon "Expected bladder capacity." Systematic review and new models for children's normal maximum voided volumes. Neurourol Urodyn. 2014;33 (7):1092-1098. doi:10.1002/nau.22452

93. Hagstroem S, Kamperis K, Rittig S, Djurhuus JC. Bladder reservoir function in children with monosymptomatic nocturnal enuresis and healthy controls. J Urol. 2006;176(2):759-763. doi:10.1016/S00225347(06)00296-5

94. Im YJ, Lee JK, Park K. Time course of treatment for primary enuresis with overactive bladder. Int Neurourol J. 2018;22(2):107. doi:10.5213/inj.1836020.010
95. Sreedhar B, Yeung CK, Leung VYF, Chu CW. Ultrasound bladder measurements in children with severe primary nocturnal enuresis: pretreatment and posttreatment evaluation and its correlation with treatment outcome. J Urol. 2008;179(4):1568-1572. doi:10.1016/j. juro.2007.11.096

96. Montaldo P, Tafuro L, Rea M, Narciso V, Iossa AC, Gado R. Desmopressin and oxybutynin in monosymptomatic nocturnal enuresis: a randomized, double-blind, placebo-controlled trial and an assessment of predictive factors. BJU Int. 2012;110(8b):E381E386. doi:10.1111/j.1464-410X.2011.10918.x

97. Radvanska E, Kovács L, Rittig S. The role of bladder capacity in antidiuretic and anticholinergic treatment for nocturnal enuresis. $J \quad$ Urol. 2006;176(2):764-769. doi:10.1016/S0022-5347(06) 00595-7

98. de Wachter S, Vermandel A, de Moerloose K, Wyndaele JJ. Value of increase in bladder capacity in treatment of refractory monosymptomatic nocturnal enuresis in children. Urology. 2002;60 (6):1090-1094. doi:10.1016/S0090-4295(02)02127-1

\section{Publish your work in this journal}

Research and Reports in Urology is an international, peer-reviewed, open access journal publishing original research, reports, editorials, reviews and commentaries on all aspects of adult and pediatric urology in the clinic and laboratory including the following topics: Pathology, pathophysiology of urological disease; Investigation and treatment of urological disease; Pharmacology of drugs used for the treatment of urological disease. The manuscript management system is completely online and includes a very quick and fair peer-review system, which is all easy to use. Visit http://www.dovepress.com/ testimonials.php to read real quotes from published authors. 